\title{
Modeling hydrodynamic behavior in fixed bed bioreactors under different hydraulic conditions via Retention Time Distribution
}

\author{
Ming Zeng ${ }^{1,2, a}$, Audrey Soric ${ }^{2, b}$ and Nicolas Roche ${ }^{2^{*}, \mathrm{c}}$ \\ ${ }^{1}$ College of Marine and Environment, Tianjin University of Science \&Technology, 300457 Tianjin, \\ China; \\ ${ }^{2}$ Aix Marseille University, Centrale Marseille, CNRS, M2P2 UMR 7340, 13545 Aix en Provence, \\ France \\ aming.zeng@tust.edu.cn, ${ }^{\mathrm{b}}$ audrey.soric@centrale-marseille.fr, ${ }^{\mathrm{c}}$ corresponding author: \\ nicolas.roche@univ-amu.fr
}

Corresponding Author: Nicolas Roche

Keywords: hydraulic parameter, RTD, BTC, saturation condition, wastewater treatment.

\begin{abstract}
In this study, effects of hydraulic conditions including hydraulic loading rate and hydraulic saturation condition in fixed bed reactor with two different porous media were investigated by retention time distribution analysis. In terms of hydraulic modeling, models of tanks in series, plug flow and their mixed combination were employed to simulate breakthrough curves. Results indicated that number of tanks and dispersion coefficient instead of actual hydraulic volume were comparatively affected by water flow rate in both unsaturated and fully saturated hydraulic conditions. Moreover the latter condition contributed to higher actual hydraulic volume and lower number of tanks, and hydraulic saturation condition impacted the selection of support media as well.
\end{abstract}

\section{Introduction}

Hydraulic conditions in wastewater treatment plants should be considered carefully in order to get high treatment efficiency of pollutants [1]. Generally, hydraulic loading rate (HLR), water flow direction and hydraulic saturation condition in reactors that are thought to determine the hydraulic behavior needs to be evaluated [2-3]. Meanwhile, it has been widely accepted that hydrodynamic behaviors can be affected by biofilm development. For example, biofilm growth leads to the clogging that normally occurs at the inlet region of a vertical biofilter, which affects treatment efficiency and lifetime of the biofilter [4]. However, there is a lack of comprehensive research to consider effects of all these factors on the hydrodynamic behavior in the same reactor currently.

Residence Time Distribution (RTD) analysis is an efficient tool to investigate hydrodynamic behavior in biofilters, which is usually carried out in three steps: (1) injecting the tracers at the inlet of reactor; (2) analyzing tracer concentration at the outlet to get breakthrough curves (BTCs); (3) fitting the observed BTCs by certain hydraulic equations with several hydraulic parameters to explain hydrodynamic behavior. Compared with single model of plug flow or tanks in series (TIS), different combinations of these models can better simulate observed BTCs [5].

The object is to investigate the effects of hydraulic conditions on the hydrodynamic behavior in fixed bed bioreactors, including hydraulic loading rate and hydraulic saturation condition. The software DTS Pro. was used to characterize hydraulic parameters and to simulate breakthrough curves that were obtained by retention time distribution analysis.

\section{Materials and methods}

Two $110 \mathrm{~cm}$-height columns were fulfilled with 2 different porous media as biofilm development carrier, respectively, one with plastic rings named PF and the other with glass beads named GF. The sketch of reactor was described by Zeng et al [6]. Plastic rings have a diameter of $10 \mathrm{~mm}$ and length of $7 \mathrm{~mm}$ with a specific surface area of $800 \mathrm{~m}^{2} . \mathrm{m}^{-3}$. Glass beads have a diameter of $4 \mathrm{~mm}$, and a 
specific surface area of $900 \mathrm{~m}^{2} \cdot \mathrm{m}^{-3}$. Three hydraulic loading rates were compared: 1,3 and $7 \mathrm{~L} \cdot \mathrm{h}^{-1}$. Two hydraulic saturation conditions were conducted in the reactor: unsaturated condition and fully saturated condition.

A concentrated $\mathrm{NaCl}$ solution of $200 \mathrm{~g} \mathrm{~L}^{-1}$ was injected at the inlet of reactor in the pulse way (10 $\mathrm{mL}$ to $60 \mathrm{~mL}$ ) to conduct RTD test. The obtained BTCs were modeled by DTS Pro. software (Version 4.20, France) that offered a user-friendly interface to implement hydraulic models by conducting fast Fourier transform.

\section{Results and discussion}

\subsection{Hydrodynamic behavior under unsaturated hydraulic condition}

Fig. 1a and $1 \mathrm{~b}$ shows experimental and modeled BTCs in the biofilters under unsaturated hydraulic condition with different HLRs. Most of tracer recoveries were around $100 \%$ (Table 1). BTCs in GF were fitted by the TIS model, while BTCs in PF were preferentially interpreted by the model of plug flow with TIS. Actual hydraulic retention time was divided into hydraulic time for plug flow $\left(\mathrm{t}_{\mathrm{plug}}\right)$ and time for tanks-in-series $\left(\mathrm{t}_{\mathrm{TIS}}\right)$. Modeled hydraulic parameters are summarized in Table 1 , which shows that unsaturated hydraulic condition contributed to a low hydraulic retention time as well as small effective volume ratio in filters. Furthermore, unsaturated condition eliminated the differences of hydraulic parameters between porous media of glass beads and plastic rings. The actual hydraulic volume ranged between 0.4 and $0.7 \mathrm{~L}$, and effective volume ratios in all treatments stayed low because the gravity water flow gives rise to a few part of available mobile volume. Furthermore, effective volume ratio was slightly higher in GF than that in PF and the hydraulic flow pattern seemed to be close to plug flow in GF with high values of $\mathrm{N}$ due to the smaller porosity in GF.
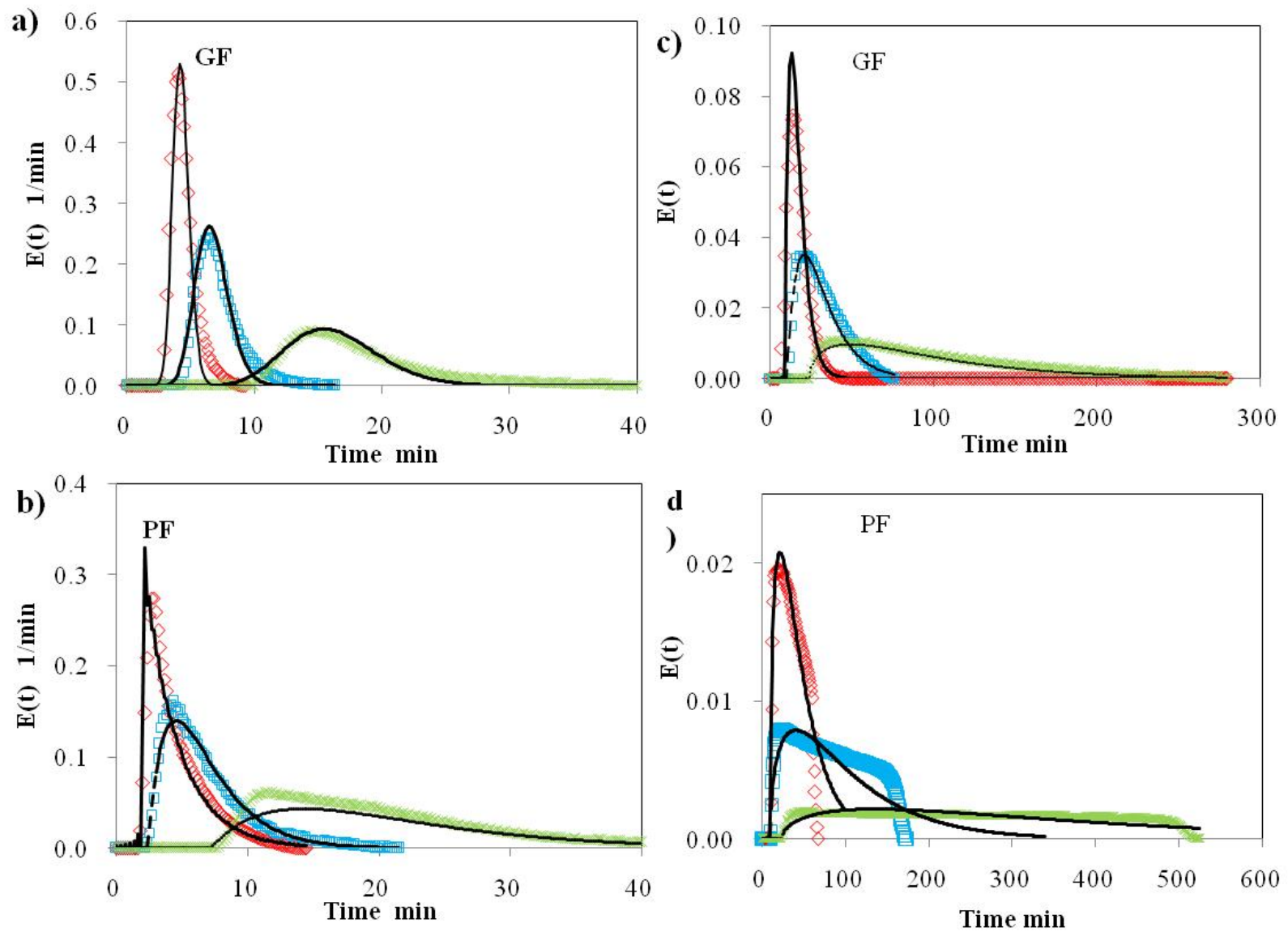

Fig. 1 Experimental and modeled BTCs in unsaturated hydraulic conditions under different HLRs in

GF (a) and PF (b), and in fully saturated hydraulic conditions under different HLRs in GF(a) and PF(b); experimental data: 7 L.h-1 $(\diamond), 3$ L.h-1 ( $\square)$, 1 L.h-1 $(\times)$; modeled data (lines) 
Effect of water flow rate on the effective volume was quite weak in unsaturated hydraulic condition, whereas its effects on number of tanks and dispersion coefficient were comparatively large (Table 1). The similar phenomenon was observed in study of Panuvatvanich et al. [2]. Their results revealed that although the hydraulic behavior of vertical flow constructed wetland system was strongly dependent on the operating pattern (feeding and drainage), but not significantly affected by the hydraulic loading rate. Furthermore, Sharvelle et al. [7] demonstrated that liquid distribution in the trickling biofilters was substantially improved at a high hydraulic loading rate of $1.9 \mathrm{~m} \mathrm{~h}^{-1}$ for all packing materials. This phenomenon is in accordance with the increase of dispersion coefficient in both filters (from 0.004 to $0.01 \mathrm{~cm}^{2} \mathrm{sec}^{-1}$ and from 0.07 to $1.07 \mathrm{~cm}^{2} \mathrm{sec}^{-1}$ in GF and PF, respectively) along with the increase of HLR (Table 1).

\subsection{Hydrodynamic behavior under fully saturated hydraulic condition}

Fig. 1c and 1d shows experimental and modeled BTCs in filters in fully saturated hydraulic condition with both porous media at different HLRs. Tracer recoveries ranged from $82 \%$ to $110 \%$ (Table 1). All BTCs were fitted by the model of plug flow with TIS. It is clear to notice that the peak of BTCs looked remarkably sharp with a short hydraulic retention time at a high HLR. According to Table 1, although actual hydraulic retention time greatly decreased at a high HLR, actual hydraulic volume stayed in nearly the same level, which indicated that HLR could not greatly change actual hydraulic volume. However, biofilm carriers contributed to different hydraulic volume that varied from 5.0 to $5.7 \mathrm{~L}$ in PF and from 1.6 to $2.0 \mathrm{~L}$ in GF. Similarly, the effective volume ratio arrived at around $75 \%$ in PF and slightly increased from $44 \%$ to $57 \%$ in GF along with the increase of HLR. The value of $\mathrm{e}_{\mathrm{v}}$ is higher in PF than that in GF, in accordance with conclusion of Sharvelle et al. [7], who found that the material with the highest specific surface area resulted in excessive formation of stagnant zones in biofilters. As a result, due to the higher specific surface area of glass beads ( 900 $\left.\mathrm{m}^{2} \cdot \mathrm{m}^{-3}\right)$ than that of plastic rings $\left(800 \mathrm{~m}^{2} \cdot \mathrm{m}^{-3}\right)$, dead zones in GF lowered its effective volume ratio.

Besides, number of stirred tanks significantly increased from 1.5 to 4 and dispersion coefficient also increased from 0.11 to $2.14 \mathrm{~cm}^{2} \cdot \mathrm{sec}^{-1}$ along with the increase of HLR in GF, which means that a higher HLR contributes to more volume for plug flow and greater water dispersion. Similarly, Martinov et al. [8] verified a power relationship between the number of mixed cells and liquid velocity in a fibrous fixed bed reactor, who found that the low flow velocity ensuring a high reactor mean residence time contributed to low $\mathrm{N}$ values between 1 and 2 . However, the change of number of stirred tanks in PF was not evident with the same value of 1.5, although the dispersion coefficient increased from 0.21 to $1.61 \mathrm{~cm}^{2} \cdot \mathrm{sec}^{-1}$, which means that the media with a large porosity helps the filter bed to resist to a great change of hydraulic loading rate.

Table 1 Hydraulic parameters under different hydraulic conditions in GF and PF

\begin{tabular}{|c|c|c|c|c|c|c|c|c|c|c|c|}
\hline $\begin{array}{l}\text { Hydraulic } \\
\text { saturation } \\
\text { condition }\end{array}$ & filter & $\begin{array}{l}\text { HLR } \\
\text { L. } h^{-1}\end{array}$ & $\begin{array}{l}\tau \\
\min \end{array}$ & $\begin{array}{l}\mathrm{t}_{\text {actual }} \\
\text { min }\end{array}$ & $\begin{array}{l}\mathrm{e}_{\mathrm{V}} \\
\%\end{array}$ & $\begin{array}{l}t_{\text {plug }} \\
\text { min }\end{array}$ & $\begin{array}{l}\mathrm{t}_{\mathrm{TIS}} \\
\mathrm{min}\end{array}$ & $\begin{array}{l}\mathrm{V}_{\text {actual }} \\
\mathrm{L}\end{array}$ & $\mathrm{N}$ & $\begin{array}{l}D \\
\mathrm{~cm}^{2} \cdot \mathrm{se} \\
\mathrm{c}^{-1}\end{array}$ & $\begin{array}{l}\mathrm{R} \\
\%\end{array}$ \\
\hline \multirow[t]{6}{*}{ Unsaturated } & GF & 1 & 210 & 22 & 10 & 0 & 22 & 0.4 & 20 & 0.004 & 105 \\
\hline & & 3 & 66 & 9 & 14 & 0 & 9 & 0.4 & 27 & 0.008 & 108 \\
\hline & & 7 & 28 & 5 & 18 & 0 & 5 & 0.6 & 45 & 0.01 & 118 \\
\hline & $\mathrm{PF}$ & 1 & 431 & 26 & 6 & 9 & 17 & 0.4 & 2 & 0.07 & 125 \\
\hline & & 3 & 133 & 8 & 6 & 3 & 5 & 0.4 & 2 & 0.23 & 100 \\
\hline & & 7 & 57 & 6 & 11 & 2 & 4 & 0.7 & 1 & 1.07 & 101 \\
\hline \multirow{6}{*}{$\begin{array}{l}\text { Fully } \\
\text { saturated }\end{array}$} & GF & 1 & 223 & 99 & 44 & 24 & 75 & 1.6 & 1.5 & 0.11 & 110 \\
\hline & & 3 & 69 & 32 & 47 & 10 & 21 & 1.7 & 2 & 0.46 & 106 \\
\hline & & 7 & 30 & 17 & 57 & 5 & 12 & 2.0 & 4 & 2.14 & 102 \\
\hline & $\mathrm{PF}$ & 1 & 444 & 357 & 80 & 24 & 333 & 5.7 & 1.5 & 0.21 & 81 \\
\hline & & 3 & 137 & 102 & 75 & 10 & 92 & 5.3 & 1.5 & 0.70 & 94 \\
\hline & & 7 & 59 & 35 & 71 & 10 & 32 & 5.0 & 1.5 & 1.61 & 82 \\
\hline
\end{tabular}




\section{Summary}

RTD analysis indicated that high water flow rate contributed to the increase of number of tanks and dispersion coefficient instead of actual hydraulic volume. In other words, flow rate determined water flow pattern rather than total volume for water flow. Meanwhile, the fully saturated hydraulic condition contributed to higher actual hydraulic volume and lower number of tanks and it reduced difference of hydraulic parameters between glass beads and plastic rings. Overall, hydrodynamic behavior of fixed bed was comprehensively interpreted and quantified parameters could be used in the following biodegradation model.

\section{Acknowledgements}

This work was supported by the Projects (2014CXLG12) and Project (10227) from Tianjin University of Science \&Technology.

\section{References}

[1]. D. Ghosh, B. Gopal, Effect of hydraulic retention time on the treatment of secondary effluent in a subsurface flow constructed wetland, Ecol. En. Vol. 36 (2010), p. 1044-1051.

[2]. A. Panuvatvanich, T. Koottatep, D. Koné, Hydraulic behaviour of vertical-flow constructed wetland under different operating conditions, Environ. Technol. Vol. 30 (2009), p. 1031-1040.

[3]. H.T. Znad, K. Katoh, Y. Kawase, High loading toluene treatment in a compost based biofilter using up-flow and down-flow swing operation, J. Hazard. Mater. Vol. 141 (2007), p. 745-752.

[4]. L. Zhao, W. Zhu, W. Tong, Clogging processes caused by biofilm growth and organic particle accumulation in lab-scale vertical flow constructed wetlands, J. Environ. Sci. Vol. 21 (2009), p. $750-757$.

[5]. T.M. Werner, R.H. Kadlec, Wetland residence time distribution modeling, Ecol. En. Vol. 15 (2000), p. 77-90.

[6]. M. Zeng, A. Soric, N. Roche, Calibration of hydrodynamic behavior and biokinetics for TOC removal modeling in biofilm reactors under different hydraulic conditions, Bioresource Technol. Vol. 144 (2013), p. 202-209.

[7]. S. Sharvelle, E. McLamore, M.K. Banks, Hydrodynamic characteristics in biotrickling filters as affected by packing material and hydraulic loading rate, J. Environ. En. Vol. 134 (2008), p. 346-352.

[8]. M. Martinov, D. Hadjiev, S. Vlaev, Liquid flow residence time in a fibrous fixed bed reactor with recycle, Bioresource Technol. Vol. 101 (2010), p. 1300-1304. 